\title{
Continuous Crystallization with Gas Entrainment: Evaluating the Effect of a Moving Gas Phase in an MSMPR Crystallizer
}

Capellades, Gerard; Duso, Alessandro; Dam-Johansen, Kim; Mealy, Michael J.; Christensen, Troels V.; Kiil, Søren

\section{Published in:}

Organic Process Research \& Development

Link to article, DOI:

10.1021/acs.oprd.8b00376

Publication date:

2019

Document Version

Peer reviewed version

Link back to DTU Orbit

Citation $(A P A)$ :

Capellades, G., Duso, A., Dam-Johansen, K., Mealy, M. J., Christensen, T. V., \& Kiil, S. (2019). Continuous Crystallization with Gas Entrainment: Evaluating the Effect of a Moving Gas Phase in an MSMPR Crystallizer. Organic Process Research \& Development, 23(2), 252-262. https://doi.org/10.1021/acs.oprd.8b00376

\section{General rights}

Copyright and moral rights for the publications made accessible in the public portal are retained by the authors and/or other copyright owners and it is a condition of accessing publications that users recognise and abide by the legal requirements associated with these rights.

- Users may download and print one copy of any publication from the public portal for the purpose of private study or research.

- You may not further distribute the material or use it for any profit-making activity or commercial gain

- You may freely distribute the URL identifying the publication in the public portal 


\section{Full Paper}

Subscriber access provided by DTU Library

\section{Continuous Crystallization with Gas Entrainment: Evaluating the Effect of a Moving Gas Phase in an MSMPR Crystallizer}

Gerard Capellades, Alessandro Duso, Kim Dam-Johansen, Michael J. Mealy, Troels V. Christensen, and Søren Kiil

Org. Process Res. Dev., Just Accepted Manuscript • DOI: 10.1021/acs.oprd.8b00376 • Publication Date (Web): 24 Jan 2019

Downloaded from http://pubs.acs.org on January 29, 2019

\section{Just Accepted}

"Just Accepted" manuscripts have been peer-reviewed and accepted for publication. They are posted online prior to technical editing, formatting for publication and author proofing. The American Chemical Society provides "Just Accepted" as a service to the research community to expedite the dissemination of scientific material as soon as possible after acceptance. "Just Accepted" manuscripts appear in full in PDF format accompanied by an HTML abstract. "Just Accepted" manuscripts have been fully peer reviewed, but should not be considered the official version of record. They are citable by the Digital Object Identifier (DOI®). "Just Accepted" is an optional service offered to authors. Therefore, the "Just Accepted" Web site may not include all articles that will be published in the journal. After a manuscript is technically edited and formatted, it will be removed from the "Just Accepted" Web site and published as an ASAP article. Note that technical editing may introduce minor changes to the manuscript text and/or graphics which could affect content, and all legal disclaimers and ethical guidelines that apply to the journal pertain. ACS cannot be held responsible for errors or consequences arising from the use of information contained in these "Just Accepted" manuscripts. 


\title{
Continuous Crystallization with Gas Entrainment: Evaluating the Effect of a Moving Gas Phase in an MSMPR Crystallizer
}

\author{
Gerard Capellades, ${ }^{,+\neq}$Alessandro Duso, ${ }^{\dagger}$ Kim Dam-Johansen ${ }^{\dagger}{ }^{+}$Michael J. Mealy, ${ }^{\ddagger}$ \\ Troels V. Christensen ${ }^{\ddagger}$ and Søren Kiil*t \\ † Department of Chemical and Biochemical Engineering, Technical University of \\ Denmark, DTU, Building 229, 2800 Kgs. Lyngby, Denmark \\ ‡ H. Lundbeck A/S, Oddenvej 182, 4500 Nykøbing Sjælland, Denmark
}

Corresponding author e-mail: sk@kt.dtu.dk. 


\section{For table of contents use only}

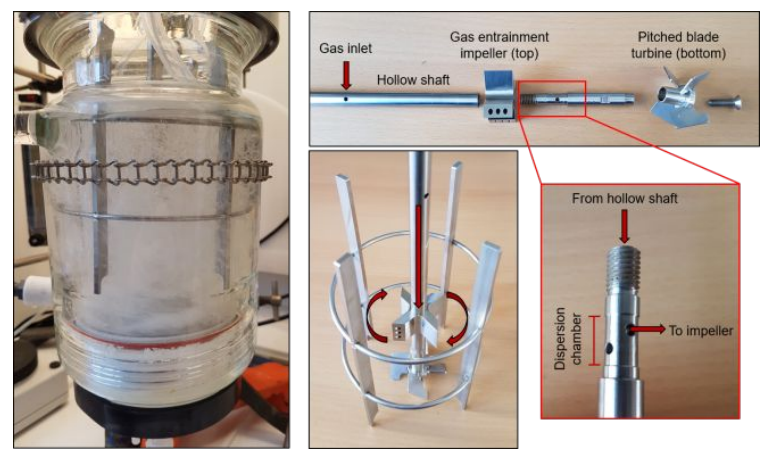




\section{ABSTRACT}

Dispersion of a saturated gas in a supersaturated solution has been previously reported to promote nucleation rates during batch crystallization, leading to the exploration of this technique as a cost-effective method to control crystal size distributions. Despite the mechanisms are still unknown, it has been hypothesized that the presence of a flowing gas could promote variations in the flow pattern inside the crystallizer, leading to improved mass transfer and higher rates of secondary nucleation through an increased number of crystal collisions. In this work, we have constructed a lab-scale MSMPR crystallizer with self-induced gas dispersion to investigate the applicability of this technique in continuous crystallization. The effect of different gas hold-ups has been evaluated at high supersaturations and for two different suspension densities. Results show a very limited variation in the overall mass deposition rate, and reductions in the mean FBRM chord length not exceeding $5 \mu \mathrm{m}$ for the highest investigated gas hold-up (12\%). Studying the effect of impeller speed under the same conditions, we found that an increased mixing intensity has a similar impact as gas dispersion, with a mean chord length reduction of 4 $\mu \mathrm{m}$ when the impeller speed was increased from 800 to $950 \mathrm{rpm}$. These results suggest that the promotion of nucleation kinetics with gas dispersion is limited to systems where crystallization kinetics can be significantly affected by mixing, and demonstrate a limited applicability for crystal size distribution control in continuous MSMPR crystallizers. 
Keywords: Melitracen hydrochloride, continuous crystallization, MSMPR, mixing, gas dispersion. 


\section{INTRODUCTION}

Understanding crystallization kinetics, particularly the nucleation rate, gives a significant advantage for the control of product properties like crystal structure or crystal size distribution. These properties are especially important for pharmaceutical processes where Active Pharmaceutical Ingredients (APIs) are subject to strict quality requirements. To achieve an adequate bioavailability, and because a large fraction of the new APIs have poor water solubility, the design of pharmaceutical crystallization processes is often tailored to the production of very small crystals with a narrow Crystal Size Distribution (CSD). ${ }^{1}$ Generation of small crystals is particularly challenging as they usually require the use of high supersaturations that lead to a poor control of the nucleation process and fouling in the industrial equipment.

Different techniques have been integrated in pharmaceutical crystallization with the aim of reducing crystal size, the most common being milling and the application of power ultrasound to promote nucleation rates. ${ }^{2-8}$ However, these techniques do not come without limitations. The use of mechanical stress for size reduction of API crystals frequently leads to significantly higher separation costs and variations in crystal shape. Furthermore, these energy intensive methods are hardly applicable with heat sensitive compounds, flammable solvents, and for those systems where a side reaction can be triggered, and their use implies an additional concern for heat dissipation. 3,9 Sonocrystallization has an additional scalability problem since the ultrasonication power 
decreases heavily with the distance from the ultrasound source. ${ }^{10,11}$ Alternative methods to produce small crystals in flow crystallization involve the generation of a local high supersaturation by means of anti-solvent addition or by combination of a hot saturated stream with a colder stream. ${ }^{12,13,14}$ These additions are usually conducted in an impinging jet or static mixer that acts as a seed generator at the beginning of the crystallization process.

Previous work studied the impact of gas dispersion on batch crystallization, reporting a significant reduction in the crystallization induction times and applicability for crystal size distribution control for different compounds and scales. ${ }^{15-19}$ Wohlgemuth et al studied the impact of gassing and power ultrasound on induction times and crystal size distributions in adipic acid crystallization, for which both techniques showed a similar crystallization behavior. ${ }^{20}$ Since then, the work on gassing crystallization has increased significantly.

In previous work, we applied induction time statistics to separate the rate of primary nucleation from the time required for the system to achieve a certain turbidity. ${ }^{21}$ We found that the shorter induction times could be a consequence of a faster rate of crystallization after the first nucleation event, when the impact of primary nucleation becomes significantly smaller. The presence of a flowing and collapsing gas offered a new perturbation and a significant mixing improvement in batch crystallizers with a transitional mixing regime $(\operatorname{Re} \approx 300)$. In this work, we evaluated if this technique could be applicable in a well mixed continuous crystallizer with impeller Reynolds numbers at the order of 12,000 . 
From an industrial perspective, the deliberate dispersion of gas in a crystallizer appears counterintuitive. Especially when the entrained gas is in the form of very small bubbles, mechanisms like flotation or gas inclusion in the crystalline phase can significantly impact the product quality and the complexity of the crystallization process. ${ }^{22}$ However, it is important not to disregard the effect of fluid dynamics on crystallization, particularly on secondary nucleation and crystal growth. In contrast with a faster impeller speed, gas dispersion promotes mass transfer without inducing crystal breakage or vortexing. In systems where the crystal growth rate is limited by mass transfer, gas dispersion becomes a simple alternative to enhance crystallization kinetics that is mild with the crystalline phase and does not necessarily require an additional separation step. Furthermore, a chaotic mixing environment caused by the presence of a flowing gas could promote crystal to crystal collisions and secondary nucleation. In contrast with other methods for generating small crystals, the nucleation rate enhancement could be done at constant supersaturations and it would be easily scalable. The gas can be captured from the crystallizer headspace by means of a hollow shaft mixer, and thus the method has significantly lower operation costs than ultrasonication or milling.

Continuous MSMPR crystallizers are subject to strict mixing requirements for the achievement of a perfectly mixed suspension and negligible classification in the product removal. In turn, operating with a well mixed homogeneous system allows for the direct application of in-situ characterization techniques to monitor the product quality. ${ }^{23,24}$ Their simplicity and ability for handling concentrated suspensions makes MSMPR crystallizers 
the preferred choice for continuous pharmaceutical crystallization. However, this type of crystallizer operates at constant conditions that are constrained by several process and system requirements. Consequently, MSMPR crystallizers are more limited for crystal size distribution control compared to batch or plug flow crystallizers. To significantly expand the attainable region of crystal sizes, one must vary the crystallization method or rely on the use of several crystallization stages. ${ }^{25}$

This study had two main objectives. First, to assess if gas dispersion is a valid alternative for crystal size distribution control in continuous MSMPR crystallizers. Second, to further develop the understanding of the effect of a moving gas phase on crystallization kinetics. To this end, a first set of experiments was designed so that the effect of gas holdup on crystallization yield and crystal size distribution could be assessed at a constant impeller speed. Results from these experiments were later compared to the effect of varying the impeller speed to investigate if there is a relationship between the effect of gas dispersion and that of a higher mixing intensity.

\section{EXPERIMENTAL SECTION}

Materials. Melitracen hydrochloride ( $\geq 99.8 \%$ purity) was obtained in powder form from the manufacturing facilities in $\mathrm{H}$. Lundbeck A/S. Its chemical structure is shown in Figure 1. Absolute ethanol ( $\geq 99.8 \%$ purity) purchased from VWR Chemicals was used as a 
solvent for the process. The solubility data for this solute-solvent system was reported elsewhere. ${ }^{26}$ The gas phase used for the study is nitrogen from the laboratory supply line.<smiles>CN(C)CCC=C1c2ccccc2C(C)(C)c2ccccc21</smiles>

Figure 1. Chemical structure of Melitracen hydrochloride.

Continuous crystallization setup. The experimental work was conducted using a coupled dissolver-crystallizer configuration as depicted in Figure 2. The dissolver and the MSMPR crystallizer are jacketed reactors with operating volumes of 1000 and $900 \mathrm{~mL}$ (excluding gas phase), respectively. 


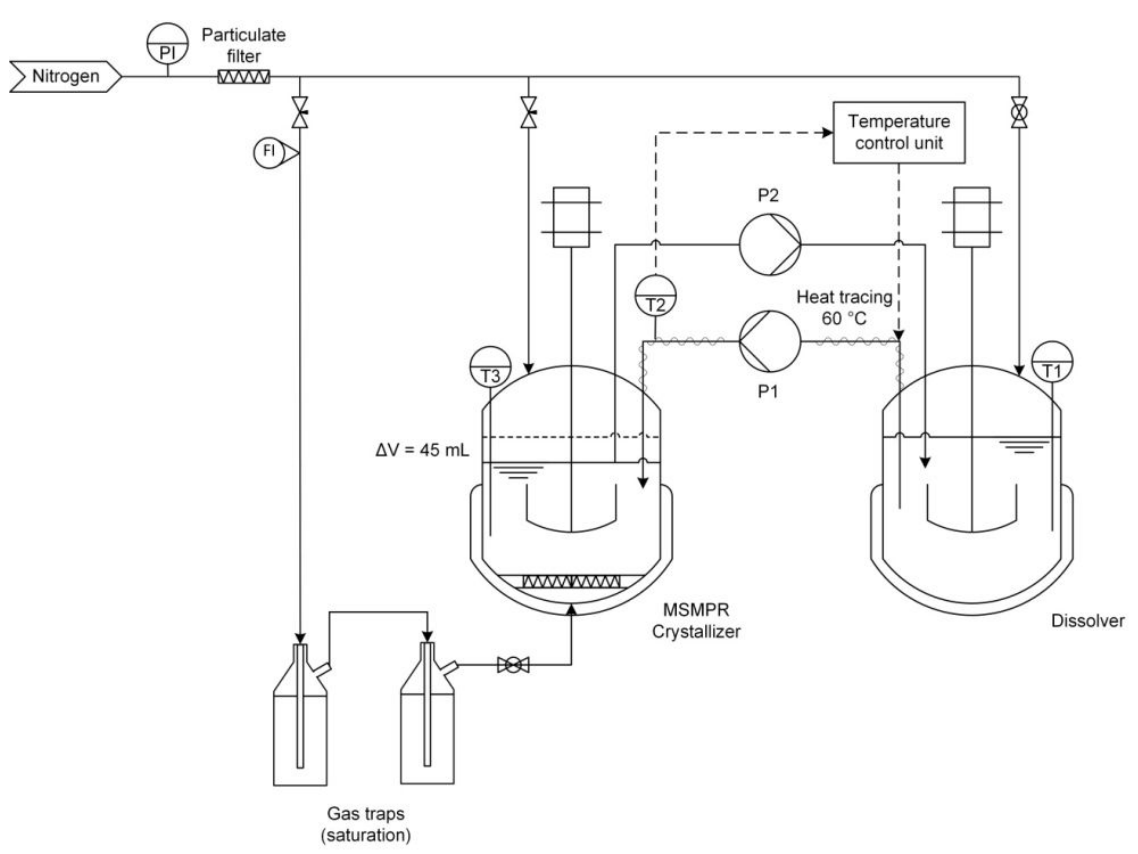

Figure 2. Schematic diagram of the setup for continuous MSMPR crystallization with gas dispersion.

An undersaturated feed was kept at $60^{\circ} \mathrm{C}$ in the dissolver during operation. $\mathrm{P} 1$ is a peristaltic pump (LongerPump BT100-1F) that continuously delivered the feed to the MSMPR crystallizer. The feed stream was heat traced to $60{ }^{\circ} \mathrm{C}$ using a temperature control unit (Lund \& Sørensen) to prevent crystallization at the tubing. Product removal was achieved using a programmable peristaltic pump (P2, LongerPump WT600-1F). An intermittent withdrawal approach was used to minimize classification in the product removal stream, by which $5 \%$ of the crystallization magma was removed every $5 \%$ of a residence time. ${ }^{27}$ This was achieved by means of a dip pipe that defines the operating volume of the crystallizer. For each withdrawal step, P2 was programmed to work at full speed $(1850 \mathrm{~mL} / \mathrm{min})$ and remove a total volume of $150 \mathrm{~mL}$. From this volume, only 45 
$\mathrm{mL}$ correspond to the crystallization magma above the dip pipe. The excess pumping was conducted to ensure that the product removal stream remained free of suspension between consecutive withdrawals.

The MSMPR crystallizer was connected to an external nitrogen supply. The nitrogen source was first passed through a $0.5 \mu \mathrm{m}$ particulate filter to prevent the introduction of solids in the MSMPR crystallizer. Then, the gas could be separated in up to three streams, leading to the bottom of the crystallizer and the headspace of each vessel. The latter were present to provide an inert environment before the experiments, but they were not active during the setup operation as they would prevent the saturation of the crystallizer headspace. To minimize solvent evaporation during gas injection, the nitrogen feed connecting to the bottom of the MSMPR crystallizer was passed through two gas traps in series, containing 250 and $100 \mathrm{~mL}$ of absolute ethanol at room temperature. During the experiments, the total pressure drop in the nitrogen line was kept below 0.8 bar to prevent significant cooling from Joule-Thomson expansion. The gas saturation was sufficient to ensure negligible solvent evaporation on the experiment time scale. This was investigated experimentally and the results can be found in supporting information.

Crystallizer design and three phase mixing. A $1000 \mathrm{~mL}$ jacketed filter reactor (Ace Glass Incorporated) was used as the MSMPR crystallizer. The vessel had a diameter of 100 $\mathrm{mm}$ and was equipped with four $8 \mathrm{~mm}$ baffles located $2 \mathrm{~mm}$ away from the crystallizer wall. The equipment was designed to operate in three different modes: (1) without gas dispersion, (2) with self-induced gas entrainment by means of a hollow shaft mixer, and 
(3) with self-induced entrainment and a bottom gas feed that was passed through a 500 $\mu \mathrm{m}$ stainless steel mesh. To isolate the effect of gas hold-up from variations in mechanical mixing, the three modes of operation shared the same impeller system and agitation speed. The baffles and impellers were designed and constructed in house using stainless steel AISI 316. The different components are shown in Figure 3.

The impeller system was divided in four components to facilitate dismantling and cleaning in case crystallization occurs in the hollow shaft, and to allow for the testing of different impeller combinations. To connect the different components, the shaft pieces are screwed together trapping the impellers in the narrow shaft regions.

Induced gas dispersion was achieved through a hollow $40 \mathrm{~mm}$ four blade radial flow impeller. The design of the impeller was inspired by the commercially available impellers from Parr Instrument. By creating a hollow path between the crystallizer headspace and the back of the impeller blades, the pressure drop generated at the back of the blades during agitation acts as the driving force to capture the gas from the crystallizer headspace and disperse it into the liquid phase. ${ }^{28}$ In this type of gas dispersion, the internal gas circulation is subject to a minimum rotation speed and the dispersion rate is a function of the agitation intensity. ${ }^{29,30}$ The minimum impeller speed for self-induced gas entrainment in this work was $650 \mathrm{rpm}$, corresponding to an approximated impeller Reynolds number of 10,000 in absolute ethanol. However, an agitation speed of $800 \mathrm{rpm}$ was selected for the experiments $(\operatorname{Re} \approx 12,000)$ as it provides the maximum gas hold-up 
with negligible vortexing. In the reference experiments without gas dispersion, the hollow shaft was covered with silicon tubing so that the gas inlet was tightly sealed.

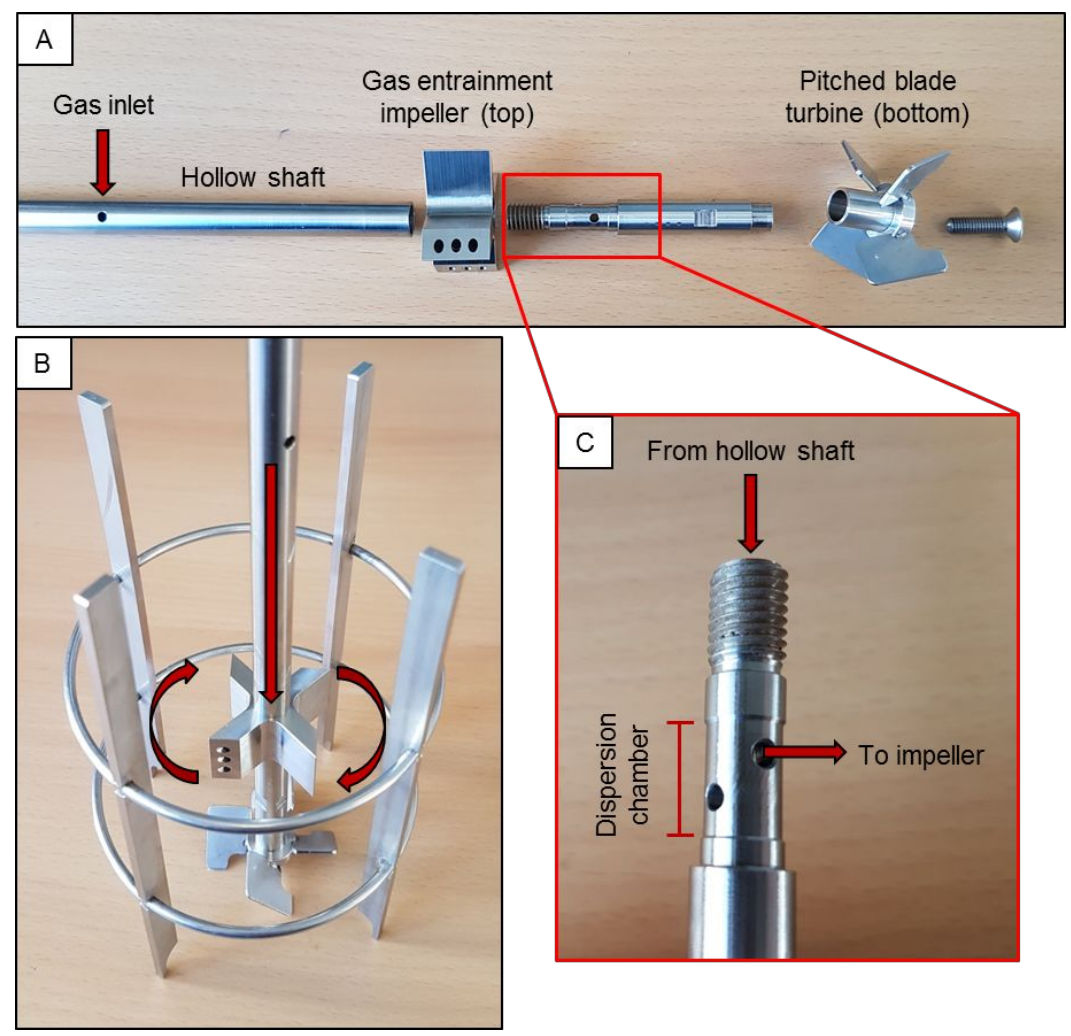

Figure 3. Designed impellers for the three phase MSMPR crystallizer. A) Components.

B) Mounted mixer and baffles. The arrows indicate the gas flow and impeller rotation. C) Close-up of the connection between the hollow shaft and the gas entrainer. When the pieces are connected $(B)$, the gas entrainment impeller is located around the dispersion chamber.

The second impeller was a solid pitched blade turbine $\left(40 \mathrm{~mm}, 4\right.$ blades, $\left.60^{\circ}\right)$, located at the bottom end of the shaft. Its main functions are to prevent solids classification at the bottom of the vessel and to assist in the dispersion of the bottom gas feed. Furthermore, the downward pumping facilitates the dispersion of gas to the bottom of the crystallizer, 
allowing for an homogenous gas dispersion even when the gas is captured by the radial flow impeller.

Methodology for the continuous crystallization experiments. The experiments in this work were conducted in the setup described in Figure 2. In all the investigated conditions, the crystallization temperature was kept at $10^{\circ} \mathrm{C}$ and the crystallization volume at $900 \mathrm{~mL}$ excluding gas phase. The position of the dip pipe for product removal was adjusted at the beginning of each experiment to account for variations in the gas hold-up. This ensured that the residence time in the crystallizer remained consistent between experiments.

The experiments started from a saturated suspension containing the same concentration in both vessels. After the feed was dissolved at $60^{\circ} \mathrm{C}$ and the crystallizer reached a temperature of $10^{\circ} \mathrm{C}$, the pumps were started at full speed for $5-10$ seconds so that the inner part of the feed tubing was preheated. Then, the feed flow rate was calibrated with a $25 \mathrm{~mL}$ graduated cylinder. Evolution to steady state was tracked using an FBRM G400 probe (Mettler Toledo) that monitors variations in the chord length distribution. Since the presence of the gas phase and the different mixing intensities can influence the FBRM measurement, the chord length distribution was measured off-line with a $45 \mathrm{~mL}$ magma sample in a magnetically agitated beaker. The beaker, sample size, agitation intensity and probe position were maintained constant between measurements to obtain comparable chord length distributions. At the working temperature and supersaturation, the mother liquor concentration was close to the saturation point at room temperature $\left(\mathrm{C}_{\mathrm{sat}, 20^{\circ} \mathrm{C}}=34.7 \mathrm{~g} / \mathrm{L}\right)^{26}$ and thus the FBRM readings were stable for few 
minutes during the off-line reading. The off-line magma sample was returned to the dissolver after the measurement.

At steady state, $4 \mathrm{~mL} \mathrm{HPLC}$ samples were taken from the feed and the crystallizer mother liquor through a $0.45 \mu \mathrm{m}$ syringe filter. Furthermore, a magma sample was analyzed with optical microscopy to detect variations in crystal shape. The sampling method was described in detail elsewhere ${ }^{26}$ All the steady state samples were taken four times at consecutive residence times and the results were averaged for the data analysis.

At the end of the experiment, the consistency of the feed flow rate was verified with a $25 \mathrm{~mL}$ graduated cylinder and the steady state classification was quantified by taking a 4 $\mathrm{mL}$ HPLC sample at three different positions in the crystallizer (top, between the two impellers, and below the second impeller). The acceptance criteria for variations in the feed flow rate was a deviation equal or lower than $0.5 \mathrm{~mL} / \mathrm{min}(2.5$ and $3.3 \%$ variation for residence times of 60 and $45 \mathrm{~min}$, respectively). Results from the classification studies are provided in supporting information.

The HPLC samples were analyzed using an Hitachi LaChrom Elite system equipped with a Phenomenex Gemini® $10 \mathrm{~cm}$ x $4.6 \mathrm{~mm}$ x $3 \mu \mathrm{m}$ C18 $110 \AA$ silica column and a L2455 diode array detector (Hitachi), with detection at $230 \mathrm{~nm}$.

\section{RESULTS AND DISCUSSION}


Consistency of the steady state and sampling accuracy. One of the main complications in the experimental work was to attain an identical feed concentration between experiments, as the extensive off-line sampling led to small variations in the dissolver concentration after several hours of operation. Such variations could lead to misleading conclusions, and thus their impact on the steady state conditions was quantified first. Three experiments were conducted at $10^{\circ} \mathrm{C}$ with a residence time of $45 \mathrm{~min}$, during which the feed concentration varied between $97 \mathrm{~g} / \mathrm{L}$ and $100 \mathrm{~g} / \mathrm{L}$. The steady state conditions are reported in Table 1.

Table 1. Steady state conditions for the three repetitions of experiment A1.

\begin{tabular}{|c|c|c|c|c|c|c|}
\hline Run & $\mathrm{C}_{0}(\mathrm{~g} / \mathrm{L})^{a}$ & w (rpm) & Gas & $\mathrm{C}_{\mathrm{ml}}(\mathrm{g} / \mathrm{L})^{a}$ & $\mathrm{M}_{\mathrm{T}}(\mathrm{g} / \mathrm{L})^{a, b}$ & $\begin{array}{c}\text { Yield }(\%)^{a} \\
, c\end{array}$ \\
\hline A1.1 & $97.5 \pm 1.5$ & 800 & No & $35.6 \pm 0.3$ & $64.4 \pm 1.8$ & $63.5 \pm 1.9$ \\
\hline A1.2 & $97.2 \pm 1.8$ & 800 & No & $36.1 \pm 0.4$ & $64.4 \pm 1.7$ & $62.9 \pm 2.2$ \\
\hline A1.3 & $\begin{array}{c}100.1 \pm \\
1.8\end{array}$ & 800 & No & $35.7 \pm 0.2$ & $67.1 \pm 0.6$ & $64.3 \pm 2.2$ \\
\hline
\end{tabular}

a The measured values include the mean \pm standard deviation of the four replicate samples of the same experiment at steady state, accounting for error propagation in the calculations. ${ }^{b}$ The crystallizer's suspension density is calculated as $\mathrm{C}_{0}-\mathrm{C}_{\mathrm{ml}} \cdot{ }^{\circ}$ The step yield is calculated as $100\left(\mathrm{C}_{0}-\mathrm{C}_{\mathrm{ml}}\right) / \mathrm{C}_{0}$. 
The steady state was reproducible with a standard deviation amongst the mother liquor concentrations of $0.3 \mathrm{~g} / \mathrm{L}(0.7 \%$ of the mean value $)$. The standard deviation amongst the three suspension densities is $1.6 \mathrm{~g} / \mathrm{L}$ ( $2.4 \%$ of the mean value), and $0.7 \%(1.1 \%$ of the mean value) for the crystallization yield. These uncertainties include the sampling and experimental error, and they account for the error propagation from the calculations. Variations in the steady state caused by the dispersion of gas will be evaluated considering that these are the minimum uncertainties in the experimental determination of the steady state conditions.

Especially when the crystal size distribution analysis is conducted off-line, experimental error during sampling combined with fluctuations in CSD during the experiment was a concern for the reproducibility of the results. Figure 4 shows the obtained square weighted chord length distributions for different steady state measurements of the same experiment and for three independent experiments. These distributions were chosen for this study as they are usually compared to a volumetric crystal size distribution during MSMPR analysis. ${ }^{31-35}$ The unweighted distributions are available as supporting information.
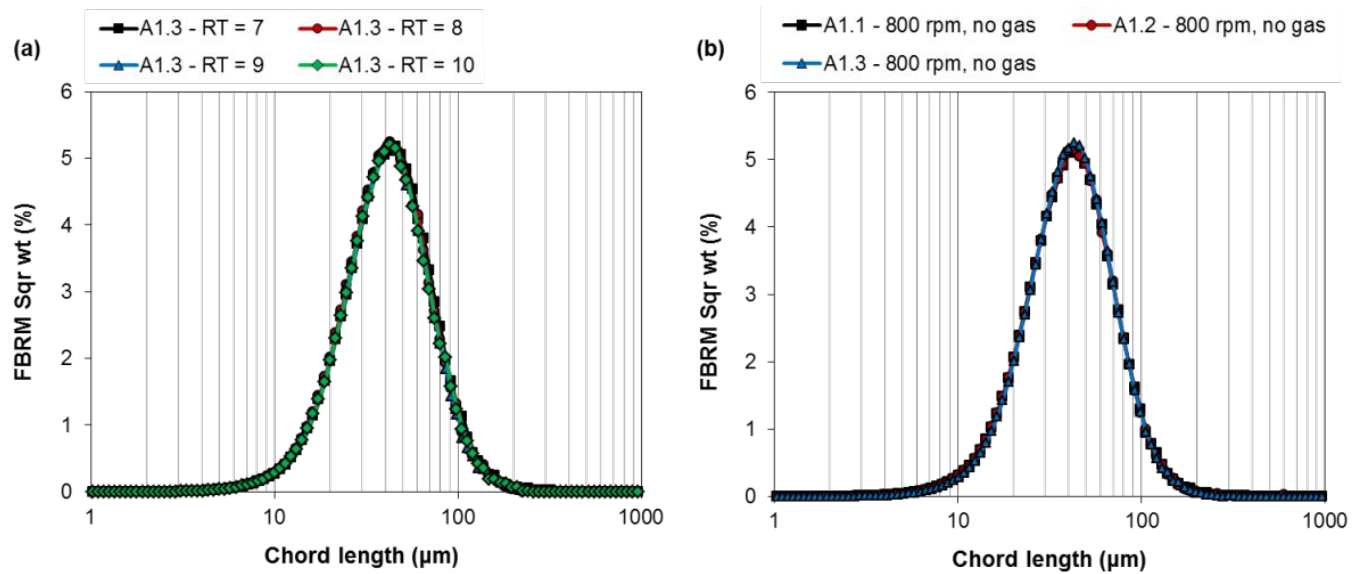
Figure 4. (a) Steady state square weighted chord length distribution for different residence times during run $\mathrm{A} 1.3$, and (b) comparison between the steady state values on the three repetitions at the same conditions. The latter distributions were obtained from the average over four consecutive residence times at steady state.

Variations in the chord length distribution are negligible in both cases, demonstrating that the sampling method is reproducible and that the steady state is consistent through small deviations in the feed concentration. The square weighted mean chord length presented a standard deviation of $0.3 \mu \mathrm{m}(0.7 \%$ of the mean value) between the triplicate experiments.

Properties of the dispersed gas. Two different gas hold-ups were investigated in this work. Their values were approximated from the increase in suspension height upon gassing and the vessel diameter. With an agitation speed of $800 \mathrm{rpm}$, self-induced gas entrainment provided an approximated gas hold-up of $4 \%$ in the crystallizer. The hold-up was increased to $12 \%$ with the injection of saturated nitrogen $(2.5 \mathrm{~L} / \mathrm{min})$ from the bottom of the crystallizer. The homogeneity of gas dispersion was assessed visually using an undersaturated solution containing $15 \mathrm{~g} / \mathrm{L}$ of Melitracen $\mathrm{HCl}$ in ethanol at $10^{\circ} \mathrm{C}$. Figure 5 shows a picture of the liquid-gas mixture with $12 \%$ hold-up. No apparent difference on bubble size was observed between the two hold-ups. 


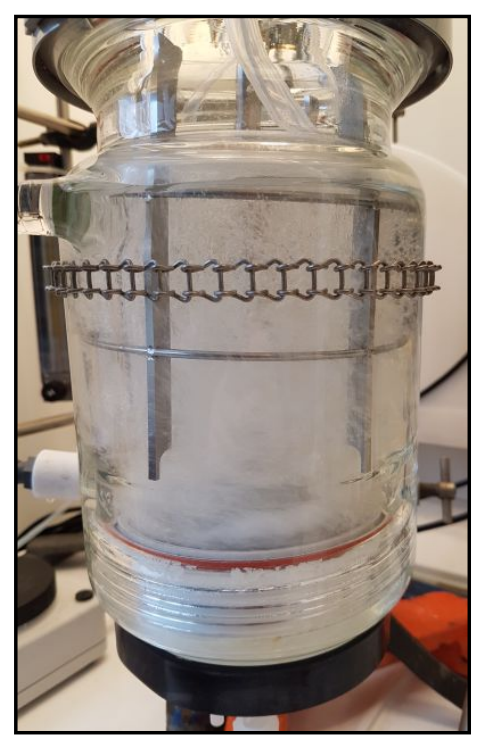

Figure 5. Gas dispersion in the MSMPR crystallizer. The picture was taken on an undersaturated API solution at $10{ }^{\circ} \mathrm{C}$. Agitation speed: $800 \mathrm{rpm}$. Flow rate (bottom injection): $2.5 \mathrm{~L} / \mathrm{min}$.

Continuous crystallization with gas entrainment. The effect of a flowing gas on MSMPR crystallization was evaluated at two different suspension densities (appr. $65 \mathrm{~g} / \mathrm{L}$ and 15 $\mathrm{g} / \mathrm{L}$ ) adjusted from the feed concentration. The objective was to separate the effects on secondary nucleation from those on primary nucleation and crystal growth. If the flowing gas was able to enhance crystal collisions and secondary nucleation, the extent of this effect would be a function of the suspension density in the crystallizer. To be able to compare the results at both suspension densities, the residence times were adjusted so that a similar steady state supersaturation was obtained in the experiments. The supersaturation value was adjusted experimentally so that it had the highest value that does not result in fouling during the experiment time frame. The steady state 


\begin{abstract}
supersaturations, calculated as $\left(C_{m l}-C_{s a t}(T)\right) / C_{s a t}(T)$, fell on the range of $0.5-0.6$ for a feed concentration of $100 \mathrm{~g} / \mathrm{L}$ and $0.4-0.5$ for a feed concentration of $50 \mathrm{~g} / \mathrm{L}$. Furthermore, the crystallization temperature was maintained at $10{ }^{\circ} \mathrm{C}$ to limit the rate of crystal growth and to minimize solvent evaporation. Based on previous work with this compound, the crystallization conditions have been optimized to minimize crystal size in the experiments without gas dispersion. ${ }^{26}$ Thus, the industrial applicability of gas dispersion can be directly compared to the best case scenario for generating small crystals in the single stage MSMPR crystallizer. A summary of the experimental conditions is provided in Table 2.
\end{abstract}

Table 2. Summary of the experimental conditions for the continuous crystallization experiments with gas dispersion. ${ }^{a}$

\begin{tabular}{|c|c|c|c|c|c|}
\hline Run & $\mathrm{C}_{0}(\mathrm{~g} / \mathrm{L})^{b}$ & $\mathrm{~T}\left({ }^{\circ} \mathrm{C}\right)$ & $\tau(\min )$ & w (rpm) & $\begin{array}{c}\text { Gas hold-up } \\
(\%)\end{array}$ \\
\hline A1.3 & $\begin{array}{c}100.1 \pm \\
1.8\end{array}$ & 10 & 45 & 800 & 0 \\
\hline $\mathrm{A} 2$ & $\begin{array}{c}100.6 \pm \\
1.6\end{array}$ & 10 & 45 & 800 & 4 \\
\hline A3 & $\begin{array}{c}101.8 \pm \\
0.6\end{array}$ & 10 & 45 & 800 & 12 \\
\hline
\end{tabular}




$\begin{array}{llllll}\text { A4 } & 52.5 \pm 1.0 & 10 & 60 & 800 & 0 \\ & & & & & \\ \text { A5 } & 49.5 \pm 1.4 & 10 & 60 & 800 & 4 \\ \text { A6 } & 50.2 \pm 0.6 & 10 & 60 & 800 & 12\end{array}$

${ }^{a}$ All the experiments were conducted with an operating volume (excluding gas phase) of $900 \mathrm{~mL}$. ${ }^{b}$ The measured feed concentration values include the mean \pm standard deviation of the four replicates at steady state.

For most of the experimental runs, the dispersion of gas did not produce complications in terms of classification or steady state stability. The sytem reached steady state within 7-9 residence times regardless of the gas hold-up, and the steady state was successfully maintained for at least four residence times before the experiments were stopped. An exception was experiment $A 6$ which was operated for 13 residence times and never reached steady state. Examination of the top of the crystallization vessel at the end of the experiment showed a large fouling ring near the suspension-headspace border. This phenomenon was much less apparent in experiment A5, and practically inexistent in experiment A3. Presumably, foam formation at the top of the vessel provided a region with poor mixing that facilitated the growth of a fouling layer at the top of the vessel. Despite the foam layer occupied a very small height in the crystallization magma (1-2 $\mathrm{mm}$ ), the use of intermittent withdrawal expanded the area of the vessel wall that is covered by the moving foam layer. The negligible impact in runs A2-3 could be explained by the shorter experiment duration and the higher solids concentration that helps to 
minimize both foam formation and regions with high supersaturation in the crystallizer. Pictures of the crystallization vessel at the end of runs $A 3, A 5$ and $A 6$ are shown in Figure 6.
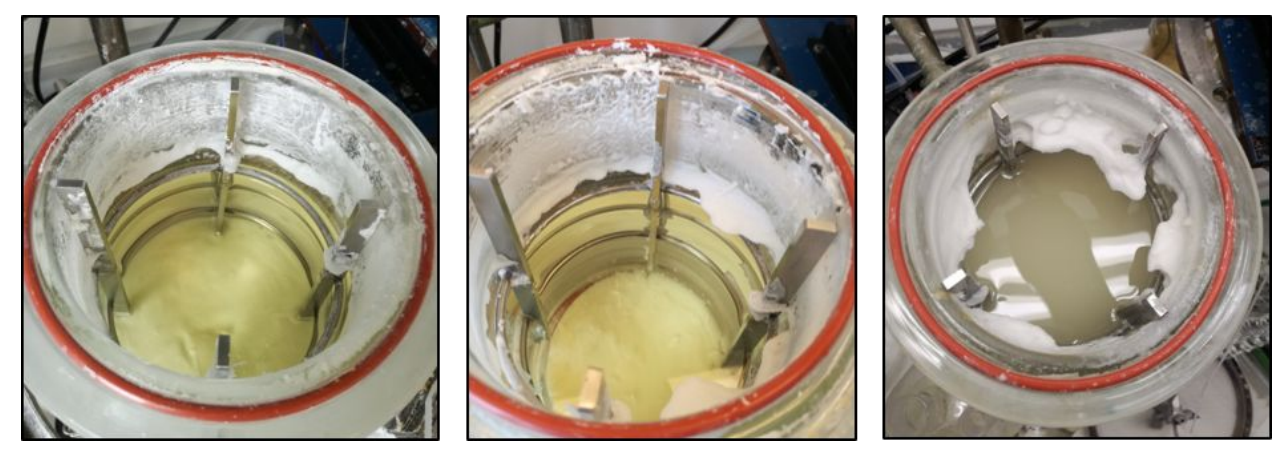

Figure 6. Crust formation at the top of the MSMPR crystallizer. Left: end of experiment A3 Middle: end of experiment A5. Right: end of the first attempt at experiment A6. None of the other experiments in this work presented this phenomenon.

Since the fouling formation did not allow the attainment of steady state in run A6, this experiment was repeated and the encrustation was removed every 30 minutes during start-up. The evolution to steady state for the first and second attempt at run A6, tracked with FBRM, is plotted together in Figure 7.

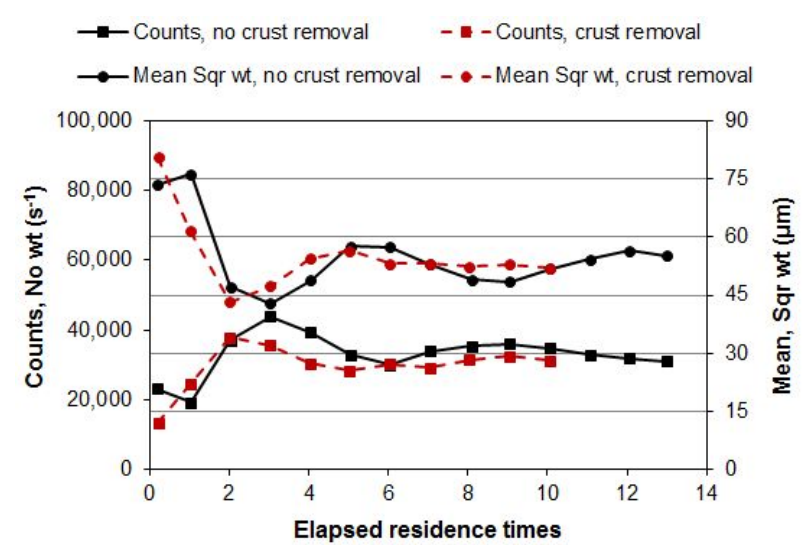


Figure 7. Evolution of the FBRM counts and square weighted mean chord length throughout the two attempts at run A6. Encrustation at the top of the crystallizer was periodically removed in the second attempt.

As it can be seen from Figure 7, removing the formed crust from the top of the vessel was an effective method to stabilize the MSMPR crystallizer during start-up. However, note that the accuracy of the experimental results is severely lower, as the user interaction can affect both the observed yield and crystal size distribution, especially when the solute suspension density is already small.

Other than the effect in fouling formation at low suspension densities, the presence of the flowing gas did not have a significant effect on the steady state classification nor on the representative product removal. This was verified using separate experiments provided in supporting information.

A sample of the microscope pictures taken for the crystallization magma is provided in Figure 8. Despite the high operating supersaturations, none of the experiments with gas dispersion presented detectable inclusions of gas bubbles in the crystal lattice. Furthermore, the crystal shape was consistent regardless of the operating conditions, and none of the experiments presented significant crystal breakage. 

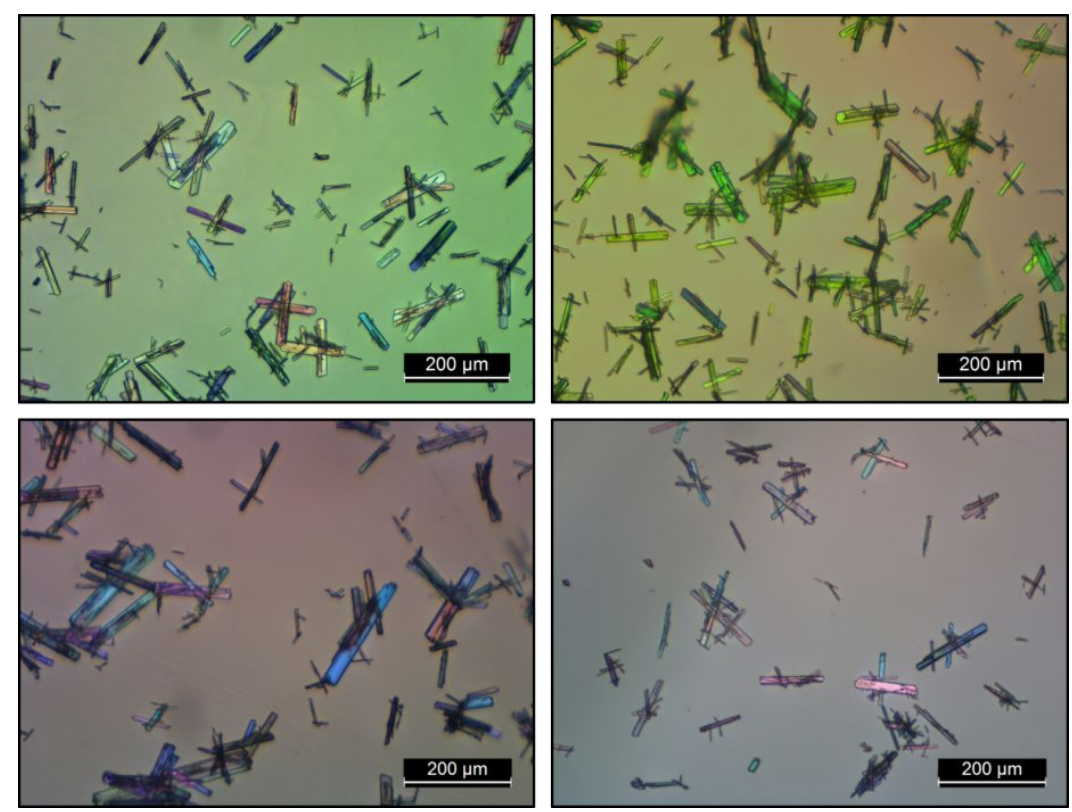

Figure 8. Microscope pictures of the crystallization magma from runs A1.3 (top left), A3 (top right), A4 (bottom left) and the second attempt at A6 (bottom right).

For a constant feed concentration, temperature and residence time, studying variations in the steady state mother liquor concentration is the most direct approach to detect variations in the overall rate of crystallization. In this work, this approach has been preferred over the study of crystal populations due to the small variations in yield and chord length distribution between experiments. Calculating the crystal populations is subject to error propagation from the experimental feed concentration, mother liquor concentration and crystal size distribution. The uncertainties are especially significant when a variation of 2-3 g/L in the feed concentration between experiments can trigger a similar variation in the steady state suspension density. As it is expected due to the significant dependence of the mass deposition rate with supersaturation, and further validated with the results in Table 1, the mother liquor concentration is a much more stable 
parameter than the suspension density through small fluctuations in the feed concentration. The steady state mother liquor concentrations have been plotted together with the saturation concentration in Figure 9.

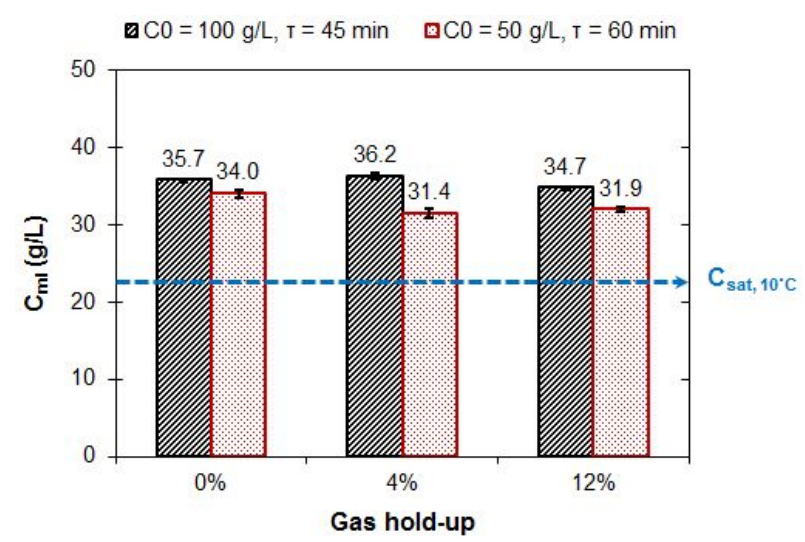

Figure 9. Effect of gas hold-up on the steady state mother liquor concentration in the MSMPR crystallizer. The error bars are calculated from the standard deviations between four consecutive samples at steady state.

From the results in Figure 9, only the dispersion of gas at low feed concentrations (A5 - A6) produced a detectable drop in the steady state mother liquor concentration. This variation would suggest a kinetic enhancement triggered by gas dispersion. However, due to the observed degree of fouling at the top of the vessel, it is complicated to assess if the dispersion of gas had an effect on crystallization yield beyond the experimental reproducibility. Even if the encrustation is limited by manual removal, its formation and growth will contribute to a higher solute mass deposition in the crystallizer.

If gas dispersion had an enhancing effect on primary nucleation or crystal growth, this effect would be consistent regardless of suspension density, especially when all the 
experiments share the same temperature and a similar supersaturation. Moreover, an effect on secondary nucleation would be more significant for the experiments at high feed concentration due to the significant dependence of this phenomenon with suspension density. Based on the results from experiments A1-3, gas dispersion has no observable impact on crystallization for the studied system. Thus, it is likely that the observed reductions for experiments A4-6 come from fouling and not from a kinetic enhancement from the gas phase.

The limited effect of gas dispersion is supported by the observed chord length distributions at steady state. As it can be observed from Figure 10, a gas hold-up of $4 \%$ in experiment A2 gave the same crystal size distribution than operating without gas dispersion (exp. A1.3). A size reduction of $5 \mu \mathrm{m}$ was observed for a gas hold-up of $12 \%$ (A3). Such reduction is significantly higher than the experiment reproducibility reported in Figure 4 , and it could have been caused by a promotion of secondary nucleation. This experiment also exhibited the smallest mother liquor concentration at the studied feed concentration. Despite the value is barely higher than the experiment reproducibility, a smaller effect in the mother liquor concentration would be expected due to the slower growth rate at lower supersaturations. The small increase in crystal size and the broadening of the chord length distribution for experiments A4-6 is to be expected, as those crystals that fall from the fouling layer will have a longer effective residence time and thus a larger size. 

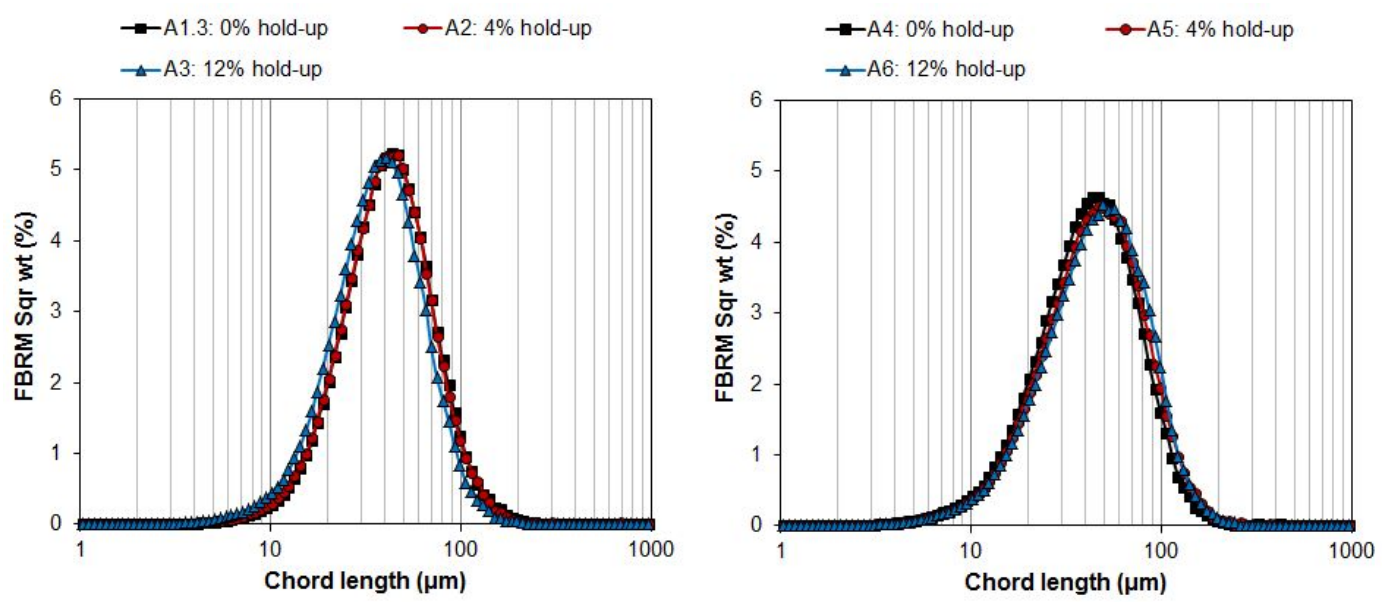

Figure 10. Effect of gas hold-up on the steady state chord length distribution in the crystallization magma. Left: Experiments at high suspension densities (A1-3). Right: Experiments at low suspension densities (A4-6).

Based on the significant amount of work that reports an effect of gas dispersion in batch crystallization, the limited effect of this technique in MSMPR crystallization is unexpected. It is important to note that, in contrast with batch crystallizers, a continuous MSMPR crystallizer operating at steady state exhibits a constant supersaturation and suspension density. The steady state is maintained by the internal feedback between crystallization kinetics and the crystal size distribution, and supersaturation plays an important role defining these parameters. When a phenomenon produces a small enhancement in crystallization kinetics, it triggers a reduction in the mother liquor concentration. This produces a drop in supersaturation that limits the net kinetic enhancement. This kind of behavior is common in continuous MSMPR crystallization and it is aggravated when the system operates close to equilibrium. Consequently, a significant change in other process 
parameters like the residence time or feed concentration often leads to small variations in the steady state mother liquor concentration. ${ }^{33,36,37}$ In this work we have operated at high supersaturations that should minimize this issue. However, there is a chance that the effects of gas dispersion are too small to produce a variation in the steady state beyond the experimental error in the determination of the steady state conditions.

Alternatively, the limited effect observed in this work could be related to the mixing conditions in the MSMPR crystallizer. It is expected that the upward-flowing gas will generate additional mixing in the magma. Nevertheless, the increased mixing intensity does not necessarily lead to a significant increase in the number of crystal impacts. Prior studies on crystal-impeller impact frequencies reported a direct dependency between the probability of collision and the local Stokes number. ${ }^{38}$ Smaller particles tend to follow the fluid streamlines rather than the sedimentation inertia. Thus, especially when the crystal size distribution is narrow, perturbating these fluid streamlines does not necessarily lead to a higher crystal-crystal collision frequency.

Finally, it is possible that despite the high operating supersaturations, the collision energy is not high enough to cause secondary nucleation. The probability of generating secondary nuclei from a crystal collision depends on the contact force applied to the parent crystal. ${ }^{39,40,41}$ If the collisions promoted by the gas phase do not have enough intensity, or if secondary nucleation relies on impeller-crystal collisions for this system, it is expected that the gas phase will have a negligible effect compared to a higher impeller speed. 


\begin{abstract}
Continuous crystallization at variable agitation speeds. To further investigate the mechanisms behind the observed behavior, the effect of varying the mixing intensity through different impeller speeds was investigated in the same setup. An impeller speed of $650 \mathrm{rpm}(\operatorname{Re} \approx 10,000$ in ethanol) was selected at the lower end, as this was the minimum agitation speed that would induce gas entrainment. Despite these experiments were conducted without gas entrainment, lower impeller speeds were not investigated as the objective was to conduct the evaluation in a mixing region that would allow for gas dispersion as an alternative. The maximum investigated impeller speed was $950 \mathrm{rpm}(\mathrm{Re}$ $\approx 14,000$ in ethanol) above which significant vortexing started to occur. The experimental conditions are summarized in Table 3.
\end{abstract}




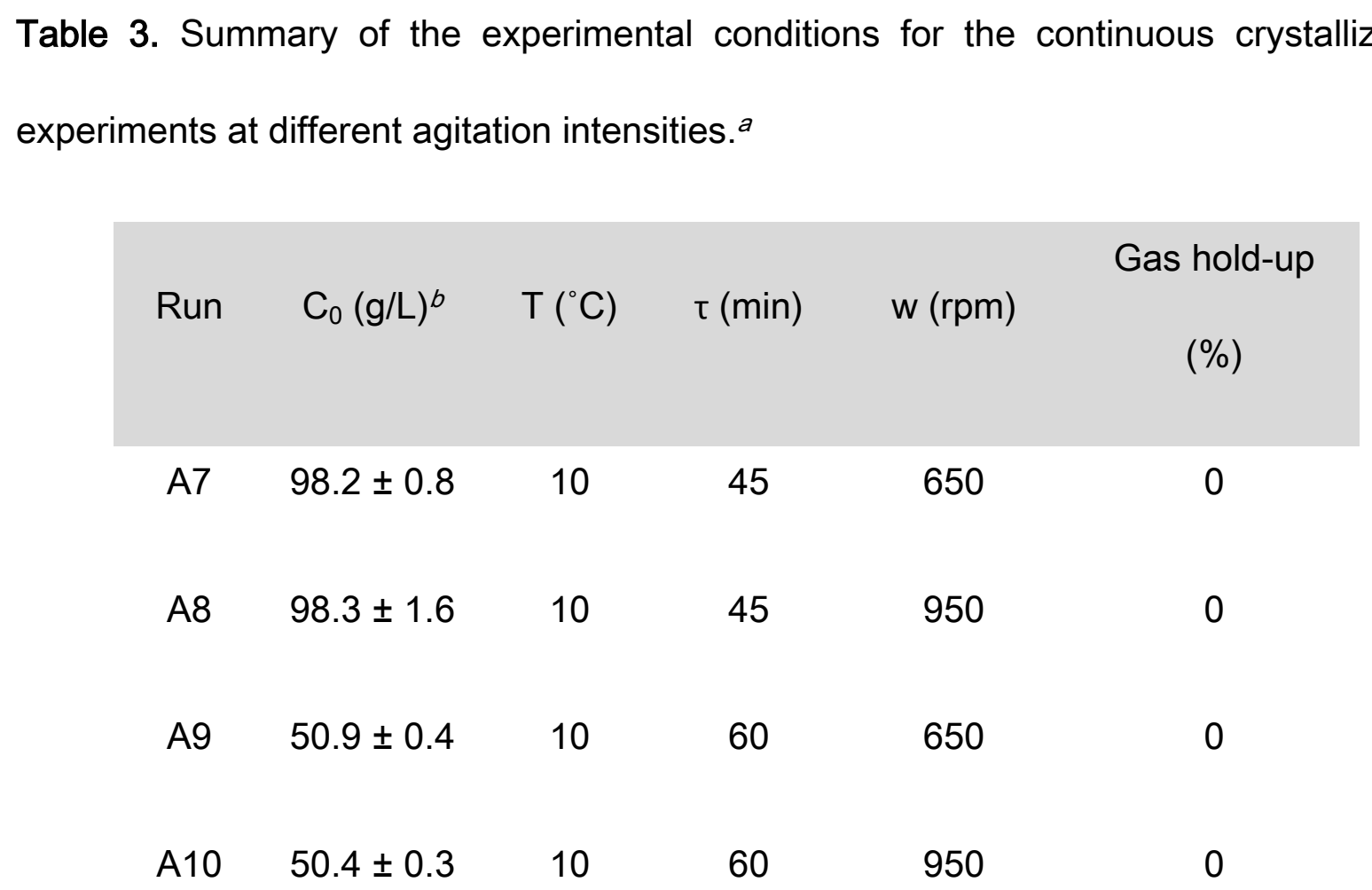

\begin{abstract}
${ }^{a}$ All the experiments were conducted with an operating volume (excluding gas phase) of $900 \mathrm{~mL}$. ${ }^{\circ}$ The measured feed concentration values include the mean \pm standard deviation of the four replicates at steady state.
\end{abstract}

The steady state mother liquor concentrations are plotted together in Figure 11. To facilitate the discussion, the results from experiments $A 1.3$ and $A 4$ (800 rpm and no gas dispersion) are included in the figure. The similarity between the obtained mother liquor concentrations indicates that there is no significant variation in the mass deposition rate caused by a higher impeller speed. These results demonstrate that, at the mixing conditions that would allow for gas dispersion in this system, crystallization kinetics cannot be further promoted by mixing. 


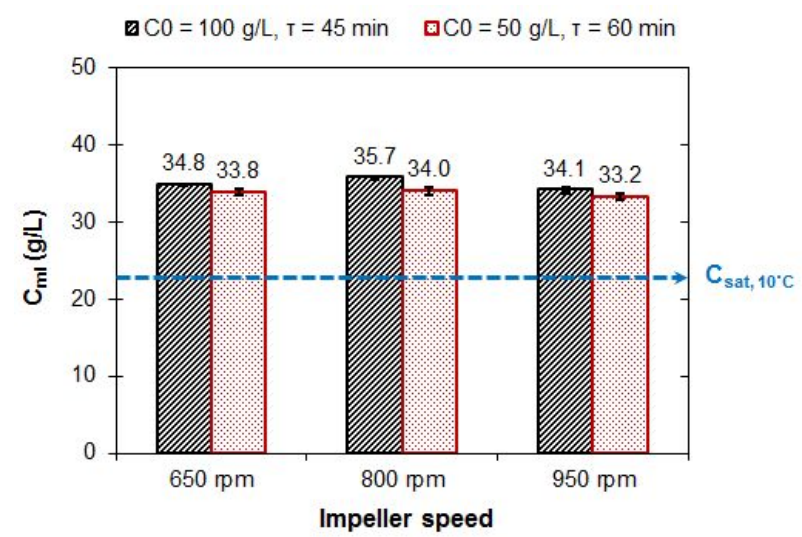

Figure 11. Effect of impeller speed on the steady state mother liquor concentration in the MSMPR crystallizer. The error bars are calculated from the standard deviations between four consecutive samples at steady state.

The steady state chord length distributions for different mixing intensities are reported in Figure 12. As expected from the negligible variations in the mother liquor concentration, the crystal size distribution is not subject to significant changes despite the variations in mixing. A $4 \mu \mathrm{m}$ reduction in the mean chord length was observed at the higher suspension density when the impeller speed was increased from $800 \mathrm{rpm}$ to $950 \mathrm{rpm}$. The chord length reduction would suggest a promotion of the secondary nucleation rate or the presence of crystal breakage. However, no significant variations in the crystal shape distribution were observed upon the analysis of 700 crystals from the optical microscopy pictures of the crystallization magma (reported in supporting information). An increased effect in crystal breakage was discarded based on this analysis. Note that the distribution obtained at $650 \mathrm{rpm}$ is very similar to the one obtained at $950 \mathrm{rpm}$. Considering that the chord length distribution is unaltered at the lower suspension densities, it is hard to believe 
that diffusion limited crystal growth would be a consequence of the increased chord lengths between $650 \mathrm{rpm}$ and $800 \mathrm{rpm}$. The observed difference is small enough to be attributed to sampling error between the experiments that were conducted at different blocks.
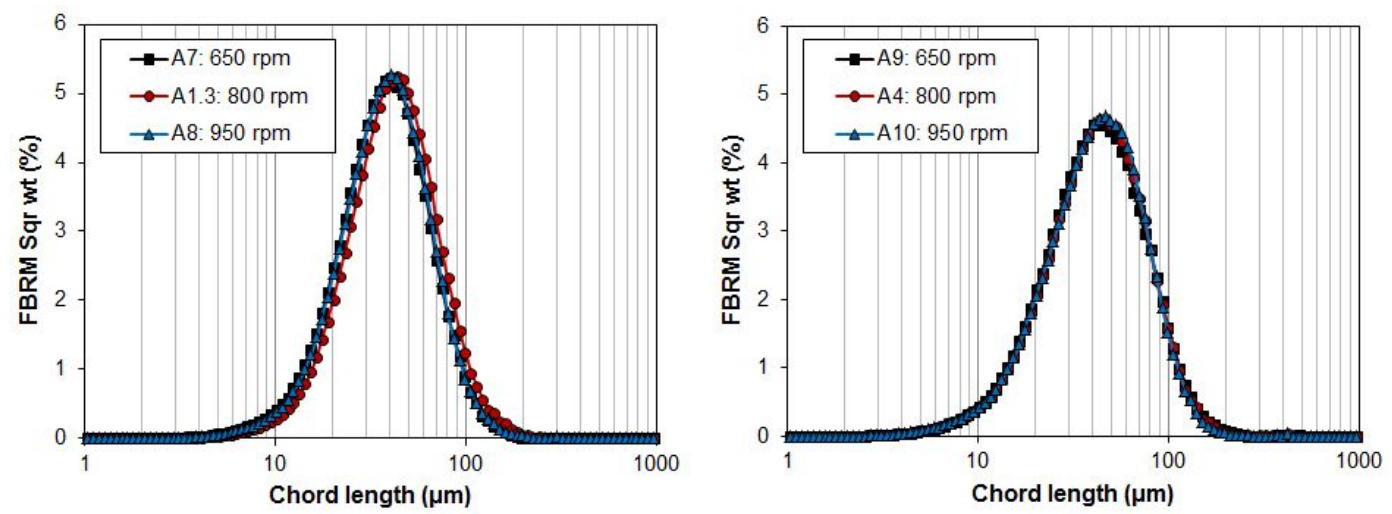

Figure 12. Effect of impeller speed on the steady state chord length distribution in the crystallization magma. Left: Experiments at high suspension densities (A1.3, A7, A8). Right: Experiments at low suspension densities (A4, A9, A10).

Increasing the stirrer speed would be expected to promote the secondary nucleation through an increased number of crystal collisions with the impellers, vessel walls, baffles and other crystals. ${ }^{38,42}$ Furthermore, were the crystal growth rate limited by diffusion, an increased mixing intensity would lead to a faster rate of crystal growth. Despite these effects, a negligible impact of mixing on crystallization kinetics has been previously reported in stirred tanks. ${ }^{43,44}$

The fact that higher mixing intensities did not lead to a significant reduction in the steady state mother liquor concentration supports that crystallization kinetics are not limited by 
diffusion, and that the rate of nucleation cannot be further promoted by mixing. Considering the high impeller velocity, it is hard to believe that the energy provided by collisions with the impeller is not sufficient to generate secondary nuclei. Thus, the negligible effect of mixing is likely a consequence of a fixed collision frequency between the crystals and other solids in the crystallizer. The already high fluid velocities in the crystallizer, combined with the small crystal sizes, facilitate that the crystals follow the fluid streamlines instead of colliding with the impeller or each other.

From the point of view of continuous pharmaceutical crystallization, results from this work have different implications. First and foremost, despite its applicability to induce nucleation in batch crystallization, gas dispersion is unlikely to be an efficient tool for reduction of crystal sizes in a well mixed continuous MSMPR crystallizer. Although the chord length distribution is simply a projection of the crystal size distribution, and the detected variations could be different for the real crystal dimensions, the observed variations in the steady state chord lengths are an order of magnitude smaller than those observed during the transient period of the same experiment (Figure 7). The homogeneous dispersion of a gas phase requires high agitation intensities, and when the aim is to generate small crystals, the crystallization conditions are already adjusted to maximize the nucleation rate. Despite these results are for just one system, it is likely that other systems will face the same problem as they would operate with high mixing intensities and small crystal sizes, for which the promotion of crystal collisions is limited by the tendency of the crystals to follow the fluid streamlines. Furthermore, continuous 
crystallizers usually deal with significantly smaller suspension densities than batch processes, thus making the promotion of crystal collisions even harder. Since the observed tendency for foam formation and fouling becomes an additional concern for the implemented process, the effect of gas dispersion must have been significantly higher to compensate the added system complexity.

\section{CONCLUSIONS}

This work was conducted to assess the industrial applicability of gas dispersion for crystal size distribution control in continuous MSMPR crystallizers. To this end, the effect of a moving gas phase on crystallization yield and crystal size distribution was investigated at high supersaturations and two different suspension densities. The crystallizer was designed to promote the formation of small crystals and to comply with the heavy demands of three phase mixing. Results from this work show that gas dispersion does not have an appreciable effect in the steady state conditions. Further investigation on the effects of mixing intensity revealed that, due to the mixing requirements in the crystallizer and the starting small crystal sizes, crystallization kinetics cannot be further promoted by mixing. Compared to previous observations in batch crystallization, results in this work support that the effectiveness of the gas dispersion technique depends on the system sensitivity towards changes in the crystallizer fluid dynamics. 


\section{ASSOCIATED CONTENT}

\section{Supporting Information}

Effect of gas injection on solvent evaporation. Preliminary mixing and product removal studies. Steady state classification in the MSMPR crystallizer. Unweighted steady state chord length distributions. Effect of agitation intensity on crystal shape. This material is available free of charge via the Internet at http://pubs.acs.org.

\section{AUTHOR INFORMATION \\ Corresponding Author \\ *E-mail: sk@kt.dtu.dk.}

\section{Author Contributions}

The manuscript was written through contributions of all authors. All authors have given approval to the final version of the manuscript.

\section{ACKNOWLEDGMENTS}

This work was financially supported by $\mathrm{H}$. Lundbeck $\mathrm{A} / \mathrm{S}$ and the Technical University of Denmark. The authors would like to thank Benjamin Petersen for his invaluable advice and assistance with the manufacturing of the gas dispersion impellers.

NOMENCLATURE 


\author{
Latin \\ $\mathrm{C}_{0} \quad$ Feed concentration, $\mathrm{g} / \mathrm{L}$ \\ $\mathrm{C}_{\mathrm{ml}} \quad$ Mother liquor concentration, $\mathrm{g} / \mathrm{L}$ \\ $\mathrm{C}_{\text {sat }}(\mathrm{T}) \quad$ Temperature dependent API solubility, g/L \\ $M_{T} \quad$ Steady state suspension density, $g / L$ \\ $\mathrm{T} \quad$ Crystallization temperature, $\mathrm{K}$ \\ w Impeller speed, min $^{-1}$ \\ Greek \\ T Residence time, min
}

\title{
REFERENCES
}

(1) Ferguson, S.; Morris, G.; Hao, H.; Barrett, M.; Glennon, B. Characterization of the Anti-Solvent Batch, Plug Flow and MSMPR Crystallization of Benzoic Acid. Chem. Eng. Sci. 2013, 104, 44-54.

(2) Eder, R. J. P.; Schrank, S.; Besenhard, M. O.; Roblegg, E.; Gruber-Woelfler, H.; Khinast, J. G. Continuous Sonocrystallization of Acetylsalicylic Acid (ASA): Control of Crystal Size. Cryst. Growth Des. 2012, 12(10), 4733-4738. 
(3) Rossi, D.; Jamshidi, R.; Saffari, N.; Kuhn, S.; Gavriilidis, A.; Mazzei, L. ContinuousFlow Sonocrystallization in Droplet-Based Microfluidics. Cryst. Growth Des. 2015, 15(11), 5519-5529.

(4) Sander, J. R. G.; Zeiger, B. W.; Suslick, K. S. Sonocrystallization and Sonofragmentation. Ultrason. Sonochem. 2014, 21 (6), 1908-1915.

(5) Yang, Y.; Song, L.; Zhang, Y.; Nagy, Z. K. Application of Wet Milling Based Automated Direct Nucleation Control in Continuous Cooling Crystallization Processes. Ind. Eng. Chem. Res. 2016, 55, 4987-4996.

(6) Yang, Y.; Song, L.; Gao, T.; Nagy, Z. K. Integrated Upstream and Downstream Application of Wet Milling with Continuous Mixed Suspension Mixed Product Removal Crystallization. Cryst. Growth Des. 2015, 15(12), 5879-5885.

(7) Narducci, O.; Jones, a. G.; Kougoulos, E. An Assessment of the Use of Ultrasound in the Particle Engineering of Micrometer-Scale Adipic Acid Crystals. Cryst. Growth Des. 2011, $11(5), 1742-1749$.

(8) Kim, S.; Wei, C.; Kiang, S. Crystallization Process Development of an Active Pharmaceutical Ingredient and Particle Engineering via the Use of Ultrasonics and Temperature Cycling. Org. Process Res. Dev. 2003, 7(6), 997-1001.

(9) Jiang, M.; Papageorgiou, C. D.; Waetzig, J.; Hardy, A.; Langston, M.; Braatz, R. D. 
Indirect Ultrasonication in Continuous Slug-Flow Crystallization. Cryst. Growth Des. 2015, 15(5), 2486-2492.

(10) Technology, C.; Ox, O.; Kingdom, U. Sonocrystallization: The Use of Ultrasound for Improved Industrial Crystallization. Org. Process Res. Dev. 2005, 9 (6), 923932.

(11) Luque de Castro, M. D.; Priego-Capote, F. Ultrasound-Assisted Crystallization (Sonocrystallization). Ultrason. Sonochem. 2007, $14(6), 717-724$.

(12) Ferguson, S.; Morris, G.; Hao, H.; Barrett, M.; Glennon, B. In-Situ Monitoring and Characterization of Plug Flow Crystallizers. Chem. Eng. Sci. 2012, 77, 105-111.

(13) Jiang, M.; Li, Y. E. D.; Tung, H. H.; Braatz, R. D. Effect of Jet Velocity on Crystal Size Distribution from Antisolvent and Cooling Crystallizations in a Dual Impinging Jet Mixer. Chem. Eng. Process. Process Intensif. 2015, 97, 242-247.

(14) Jiang, M.; Zhu, Z.; Jimenez, E.; Papageorgiou, C. D.; Waetzig, J.; Hardy, A.; Langston, M.; Braatz, R. D. Continuous-Flow Tubular Crystallization in Slugs Spontaneously Induced by Hydrodynamics. Cryst. Growth Des. 2014, 14 (2), 851860.

(15) Wohlgemuth, K.; Kordylla, A.; Ruether, F.; Schembecker, G. Experimental Study of the Effect of Bubbles on Nucleation during Batch Cooling Crystallization. Chem. 
Eng. Sci. 2009, 64 (19), 4155-4163.

(16) Ceyhan, A.; Baytar, O.; Pehlivan, E. Effects of Different Gas Phases and Gas Bubbles on the Nucleation Kinetics. Acta Chim. Slov. 2014, 61 (2), 391-397.

(17) Kleetz, T.; Funke, F.; Sunderhaus, A.; Schembecker, G.; Wohlgemuth, K. Influence of Gassing Crystallization Parameters on Induction Time and Crystal Size Distribution. Cryst. Growth Des. 2016, 16(12), 6797-6803.

(18) Kleetz, T.; Pätzold, G.; Schembecker, G.; Wohlgemuth, K. Gassing Crystallization at Different Scales: Potential to Control Nucleation and Product Properties. Cryst. Growth Des. 2017, $17(3)$, 1028-1035.

(19) Kleetz, T.; Braak, F.; Wehenkel, N.; Schembecker, G.; Wohlgemuth, K. Design of Median Crystal Diameter Using Gassing Crystallization and Different Process Concepts. Cryst. Growth Des. 2016, 16 (3), 1320-1328.

(20) Wohlgemuth, K.; Ruether, F.; Schembecker, G. Sonocrystallization and Crystallization with Gassing of Adipic Acid. Chem. Eng. Sci. 2010, 65 (2), 10161027.

(21) Capellades, G.; Kiil, S.; Dam-Johansen, K.; Mealy, M. J.; Christensen, T. V.; Myerson, A. S. Effect of Air Injection on Nucleation Rates: An Approach from Induction Time Statistics. Cryst. Growth Des. 2017, 17, 3287-3294. 
(22) Soare, A.; Lakerveld, R.; Van Royen, J.; Zocchi, G.; Stankiewicz, A. I.; Kramer, H. J. M. Minimization of Attrition and Breakage in an Airlift Crystallizer. Ind. Eng. Chem. Res. 2012, 51 (33), 10895-10909.

(23) Powell, K. A.; Saleemi, A. N.; Rielly, C. D.; Nagy, Z. K. Monitoring Continuous Crystallization of Paracetamol in the Presence of an Additive Using an Integrated PAT Array and Multivariate Methods. Org. Process Res. Dev. 2016, 20 (3), 626636.

(24) Powell, K. a.; Saleemi, A. N.; Rielly, C. D.; Nagy, Z. K. Periodic Steady-State Flow Crystallization of a Pharmaceutical Drug Using MSMPR Operation. Chem. Eng. Process. Process Intensif. 2015, 97, 195-212.

(25) Vetter, T.; Burcham, C. L.; Doherty, M. F. Regions of Attainable Particle Sizes in Continuous and Batch Crystallization Processes. Chem. Eng. Sci. 2014, 106, 167180.

(26) Capellades, G.; Joshi, P. U.; Dam-Johansen, K.; Mealy, M. J.; Christensen, T. V.; Kiil, S. Characterization of a Multistage Continuous MSMPR Crystallization Process Assisted by Image Analysis of Elongated Crystals. Cryst. Growth Des. 2018, 18, 6455-6469.

(27) Alvarez, A. J.; Singh, A.; Myerson, A. S. Crystallization of Cyclosporine in a Multistage Continuous MSMPR Crystallizer. Cryst. Growth Des. 2011, 11 (10), 
4392-4400.

(28) Martin, G. Q. Gas-Inducing Agitator. Ind. Eng. Chem. Process Des. Dev. 1972, 11 (3), 397-404.

(29) Joshi, J. B.; Sharma, M. M. Mass Transfer and Hydrodynamic Characteristics of Gas Inducing Type of Agitated Contractors. Can. J. Chem. Eng. 1977, 55, 683695.

(30) Sawant, S. B.; Joshi, J. B. Critical Impeller Speed for the Onset of Gas Induction in Gas-Inducing Types of Agitated Contactors. Chem. Eng. J. 1979, 18, 87-91.

(31) Ferguson, S.; Ortner, F.; Quon, J.; Peeva, L.; Livingston, A.; Trout, B. L.; Myerson, A. S. Use of Continuous MSMPR Crystallization with Integrated Nanofiltration Membrane Recycle for Enhanced Yield and Purity in API Crystallization. Cryst. Growth Des. 2013, 14 (2), 617-627.

(32) Lai, T. C.; Cornevin, J.; Ferguson, S.; Li, N.; Trout, B. L.; Myerson, A. S. Control of Polymorphism in Continuous Crystallization via Mixed Suspension Mixed Product Removal Systems Cascade Design. Cryst. Growth Des. 2015, 15, 3374-3382.

(33) Lai, T. C.; Ferguson, S.; Palmer, L.; Trout, B. L.; Myerson, A. S. Continuous Crystallization and Polymorph Dynamics in the L - Glutamic Acid System. Org. Process Res. Dev. 2014, $18(11), 1382-1390$. 
(34) Li, J.; Trout, B. L.; Myerson, A. S. Multistage Continuous Mixed-Suspension, MixedProduct Removal (MSMPR) Crystallization with Solids Recycle. Org. Process Res. Dev. 2016, $20(2), 510-516$.

(35) Quon, J. L.; Zhang, H.; Alvarez, A.; Evans, J.; Myerson, A. S.; Trout, B. L. Continuous Crystallization of Aliskiren Hemifumarate. Cryst. Growth Des. 2012, 12 (6), 3036-3044.

(36) Hou, G.; Power, G.; Barrett, M.; Glennon, B.; Morris, G.; Zhao, Y. Development and Characterization of a Single Stage Mixed-Suspension, Mixed-Product-Removal Crystallization Process with a Novel Transfer Unit. Cryst. Growth Des. 2014, 14 (4), 1782-1793.

(37) Power, G.; Hou, G.; Kamaraju, V. K.; Morris, G.; Zhao, Y.; Glennon, B. Design and Optimization of a Multistage Continuous Cooling Mixed Suspension, Mixed Product Removal Crystallizer. Chem. Eng. Sci. 2015, 133, 125-139.

(38) Kee, K. C.; Rielly, C. D. Measurement of Particle Impact Frequencies and Velocities on Impeller Blades in a Mixing Tank. Chem. Eng. Res. Des. 2004, 82 (A9), 12371249.

(39) Clontz, N. A.; McCabe, W. L. No Title. Chem. Eng. Prog. Symp. Ser. 1971, 67, 110.

(40) Bauer, L. G.; Larson, M. A.; Dallons, V. J. Contact Nucleation of MgSO4.7H2O in 
a Continuous MSMPR Crystallizer. Chem. Eng. Sci. 1974, 29 (5), 1253-1261.

(41) Tai, C. Y.; McCabe, W. L.; Rousseau, R. W. Contact Nucleation of Various Crystal Types. A/ChE J. 1975, 21 (2), 351-358.

(42) Melia, T. P.; Moffitt, W. P. Secondary Nucleation from Aqueous Solution. Ind. Eng. Chem. Fundam. 1964, 3 (4), 313-317.

(43) Ting, H. H.; McCabe, W. L. Supersaturation and Crystal Formation in Seeded Solutions. Ind. Eng. Chem. 1934, 26 (11), 1201-1207.

(44) Sikdar, S. K.; Randolph, A. D. Secondary Nucleation of Two Fast Growth Systems in a Mixed Suspension Crystallizer: Magnesium Sulfate and Citric Acid Water Systems. A/ChE J. 1976, $22(1), 110-117$. 